\title{
Life as a general practitioner
}

\author{
Jacqui Wise
}

The BMJ

A GP is usually the first person a patient turns to for help and is a general expert in adult and paediatric medicine. One of the attractions of working as a GP is the variety-you never know who is going to walk through the door. Yes, there will undoubtedly be a lot of backaches and colds to deal with but a GP also needs to be able to spot red flag symptoms that might indicate a serious problem such as cancer.

\section{The working day}

A GP's working week is divided up into sessions, each lasting half a day. A typical day will start at 8 am but could be earlier if the practice offers an early morning clinic. Appointments are usually 10 minutes long and the GP may see 18 to 20 patients during a morning surgery.

The time before and after the morning surgery may be spent dealing with paperwork such as going through correspondence, discharge summaries, out of hours reports, and test results. The GP may also need to make phone calls to patients or other healthcare professionals. After lunch the GP may need to visit patients at home or in care homes.

Afternoon surgery usually runs from 3 pm until 5.30 pm with another 15 to 20 patients seen. Some practices may also take last minute urgent cases after that or run late evening clinics. The working day could finish anytime from 6 to $8 \mathrm{pm}$.

Some GPs also work on Saturday mornings on a rota. The working hours of salaried and locum GPs are limited to 48 by the European Working Time Directive. As GP partners are self employed the directive does not apply to them.

\section{The patient consultation}

The number of patients looked after by a GP varies-the average is around 1800. GPs manage the healthcare of all their patients, including acute physical problems, chronic conditions, and mental health problems.

During the typical 10 minute appointment the GP needs to make a swift and accurate assessment based on the patient's symptoms and medical history. Depending on the examination and diagnosis the GP has several management options which they will need to discuss with the patient as they develop a shared and agreed plan.

This may include giving reassurance, providing information, advising on a course of action, or prescribing drugs. The GP may need to refer the patient for further tests to confirm a diagnosis or to a specialist in secondary care.
Another important part of the work is preventative medicine and health promotion, which can include giving lifestyle advice during a consultation. The growing and ageing population means GPs are increasingly dealing with multimorbidity as well as coordinating long term care. There is increasing use of telephone consultations and the shift to using different media such as video calls is likely to expand in the future.

\section{Different types of GP}

Salaried GPs are employed by the practice or primary care organisation and receive a salary of between $£ 57655$ and $£ 87003$. They also receive sick pay, holiday, and maternity pay. Salaried GPs are mostly involved with clinical work and have less say in the way a practice is run

GP partners are self employed and effectively run the practice as a small business. They receive a share of the profits and so have the potential for higher earnings. They pay their own tax and do not get benefits such as sick pay, holiday, and maternity pay. They share responsibility with the other partners for staffing, performance management, premises, and financial accountability

Locum GPs temporarily provide services where there is a short term need, such as if a practice is short staffed or a GP is absent. They are usually paid for each session they work.

\section{Teamwork}

GPs work as part of large multidisciplinary teams which may include other GPs, practice nurses, healthcare assistants, physician associates, receptionists, and other staff. They may also work closely with other healthcare professionals such as phlebotomists, midwives, community nurses, health visitors, physiotherapists, occupational therapists, speech therapists, mental health and other specialist nurses, dietitians, counsellors, and community pharmacists. GPs may also work closely with hospital doctors and social workers.

\section{Working with other practices}

An increasing number of GP practices are in some kind of collaborative arrangement with other practices. Primary care networks-small networks of neighbouring general practices working together as multidisciplinary teams-are one of the major tenets of the NHS's recent long term plan. ${ }^{12}$ These are based on geography and typically serve between 30000 and 50 000 patients. They aim to foster better collaboration among practices, pharmacists, district nurses, physiotherapists, social care, the voluntary sector, and others. These primary care networks are not statutory bodies and they differ from GP federations, which are usually larger provider groups that cover populations of around 200000 . The BMA (www.bma.org.uk/ 
advice/employment/gp-practices/gps-and-staff/gp-networks/gpnetworks) and the Royal College of General Practitioners (https: //gpatscale.rcgp.org.uk) have more information.

\section{Revalidation}

Once you hold a licence to practise to work as a GP in the UK you are legally required to revalidate. This is usually every five years and is based on having an annual appraisal in line with the GMC's core guidance for doctors (www.gmc-uk.org/-/media/ documents/revalidation-guidance-for-doctors_pdf-54232703. pdf). Your local area team or health board will support you with appraisal and revalidation. The RCGP provides a lot of supporting information for appraisal and revalidation (www. rcgp.org.uk/training-exams/practice/revalidation.aspx).

\section{Attractions of being a GP}

The opportunity to undertake a variety of work with all age groups, types of disease, and problems

The work can be very rewarding. GPs provide continuity of care-building trusting relationships with patients and their families over a long period

GPs can reach a relatively high income early in their career and it is one of the specialties most suited to part time or flexible working. There are

a higher proportion of women in general practice than in hospital medicine.
}

\section{Challenges of being a GP}

The growing workload can be challenging, especially dealing with complex psychosocial and medical problems within the standard 10 minute

consultation, and the RCGP has called for consultations to be extended to 15 minutes, or longer for those who need it (www.bmj.com/content/365/ bmj.12270)

Keeping up to date with the enormous range of diseases and service changes can be difficult

Stress and burnout can be a factor and it is vital that GPs look after their own health and wellbeing. The RCGP has a First5 initiative to support GPs in the first five years after qualifying (www.rcgp.org.uk/first5). Health Education England's GP fellowships programme provides additional support and development for newly qualified GPs or those in their first few years of practice (www.hee.nhs.uk/our-work/gp-fellowships). For help with problems relating to stress or depression, or an addiction problem that might affect work, contact the NHS GP Health Service (https:// gphealth.nhs.uk) or BMA wellbeing support services (www.bma.org.uk/ advice/work-life-support/your-wellbeing/counselling-and-peer-support)

1 NHS England. The NHS long term plan. Jan 2019. www.longtermplan.nhs.uk/wp-content/ uploads/2019/01/nhs-long-term-plan.pdf.

2 lacobucci G. The rise of primary care networks. BMJ 2019;364:I304 10.1136/bmj.I304 30665941

Published by the BMJ Publishing Group Limited. For permission to use (where not already granted under a licence) please go to http://group.bmj.com/group/rights-licensing/ permissions 